\title{
Molecular Effects of Chondroitin Sulfate in Osteoarthritis and Herniated Discs
}

\author{
Lila $\mathrm{AM}^{1^{*}}$, Gromova $\mathrm{OA}^{2}$, Torshin $\mathrm{IY}^{3}$ and Montell $\mathrm{E}^{4}$ \\ ${ }^{1}$ V.A. Nasonova Research Institute of Rheumatology, Moscow, Russia \\ ${ }^{2}$ Federal Research Center "Informatics and Control" of the Russian Academy of Sciences \\ ${ }^{3}$ Federal Research Center "Informatics and Control" of the Russian Academy of Sciences
}

${ }^{4} R \& D$, Bioibérica S.A.U.

Received: July 09, 2018; Accepted: July 30, 2018; Published: August 07, 2018

*Corresponding author: Aleksandr M. Lila, V.A. Nasonova Research Institute of Rheumatology, Moscow, Russia. E-mail: amlila@mail.ru

\begin{abstract}
Background: Chondroitin sulfate (CS) is a glycosaminglycan constructed of repeating disaccharide units with the presence of an amino sugar and different sulfated positions. This compound is present in the extracellular matrix especially in the cartilage, skin, blood vessels, ligaments and tendons. CS aside of being a building material for the cartilage it also has anti-inflammatory and antioxidant effects. For these reasons CS is currently being therapeutically used for the treatment of osteoarthritis $(\mathrm{OA})$ in many countries under the commercial name Chondroguard $®$.
\end{abstract}

Aims: This review critically analyzes the therapeutic properties of CS in the vertebral unit by assessing relevant in vitro and in vivo data published during the last decades in the specialized literature. The molecular-physiological mechanisms of action of CS in intervertebral disc extrusions and protrusions, in inflammation and neuroprotection are discussed.

Conclusions: The clinical data obtained during years of treatment with CS and the utility of this molecule to protect the functional spinal unit are also considered to highlight their potential to treat $\mathrm{OA}$ worldwide.

Keywords: Chondroitin sulfate; Osteoarthritis; Chondroguard Herniated discs.

\section{Introduction}

Homeostasis of intervertebral discs is based on the balance of all constituent components. Blood supply disturbance, increased intensity of systemic inflammation, deficiency of hyaluronic acid, glucosamine sulfate (GS) and chondroitin sulfate (CS) lead to degenerative changes in the spine [1]. A sharp pain syndrome and persistent neurologic drop-out of motor and sensory functions is associated with spinal disc herniation. Surgical removal of the hernia does not stop the degenerative process and does not exclude the possibility of recurrent disc herniation. Conservative therapy for spinal disc herniation provides for the support of cartilage connective tissue turnover (chondroprotection) using molecular components of connective tissue such as CS. CS are produced by chondrocytes and are the central components of the "gel base" of cartilage, ligament, muscles, bone, and synovial fluid. CS molecules are polymers consisting of long polysaccharides containing repeating disaccharide units (Figure 1a). Each of these units includes $\mathrm{N}$-acetyl glucosamine and D-glucuronic acid and can be sulfated (form an ester with an anion of sulfuric acid). CS differ in length, characterized by the number of polymerization ( $n$, the number of repeats of disaccharide units: $n=20-200$ ) and the degree of sulfation, which causes differences in the molecular weight of CS. This is the reason why it is more accurate to speak about chondroitin sulfates. From a pharmacological point of view, CS are chondroprotective agents promoting active cartilage regeneration; CS increase the elasticity and mechanical strength of cartilage, tendons, provide hydration and accumulation of hyaluronic acid and anti-inflammatory cytokines in cartilage and synovial joints [2-7]. Results of metaanalyses in clinical trials pointed out the high efficiency of CS in the treatment of cartilage-affecting diseases [2]. To investigate the real implications of CS effects on the human organism it is of major importance to study the effects of CS from a post genomic perspective (Figure 1b), i.e., the effects on genome (the entire set of all human genes), transcriptase (the set of all RNA molecules), proteome (the entire set of proteins expressed by a genome) and metabolome (the complete set of metabolites) as CS is not a simple protein synthesized to promote direct or immediate effects. In this review, we present the results of a systematic analysis of the molecular mechanisms of CS action, including bioinformatic genome analysis, pharmacoproteomic studies of the CS effects, data about the anti-arthritic, anti-inflammatory effect of CS, pharmacokinetics, and pharmacological safety of CS from various sources and composition. The results of the pharmacological analysis of Chondroguard $\AA$ composition and its effects on inflammation, and the mechanisms of action of CS on the formation and composition of the muscular and connective tissue and the synovial and cerebro-spinal fluid (CSF) are also presented. (Figure 1) 


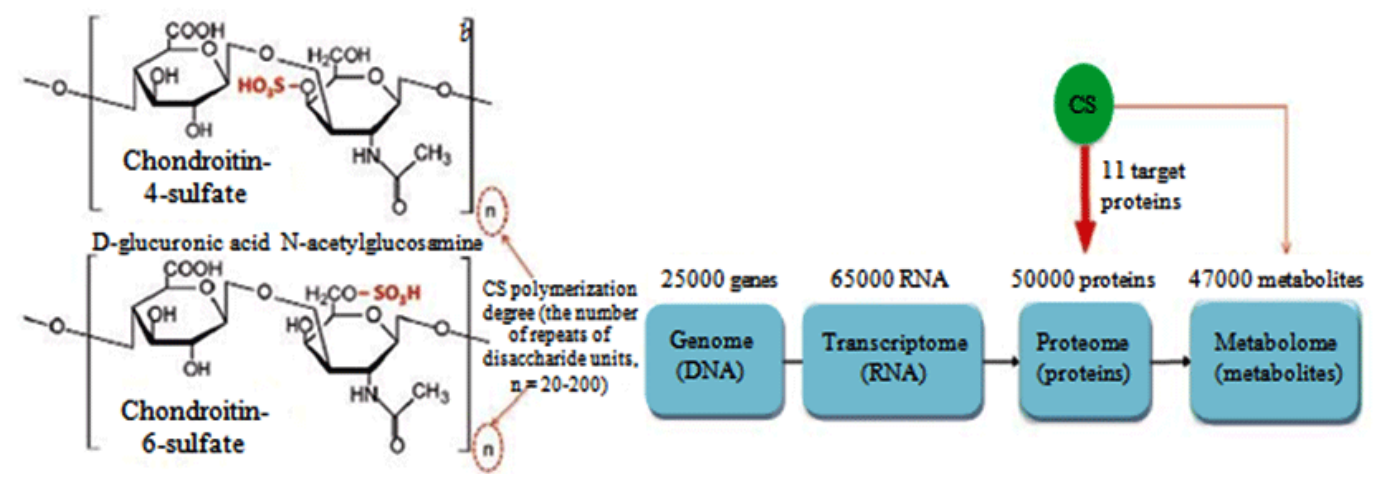

Figure 1: Chemical structure (a) and biological effects of CS from a post-genomic perspective (b)

Bioinformatic Analysis of Human Genome and Proteome and Mechanisms of CS Action

For a detailed description of the biological and pharmacological mechanisms of CS, possible interactions of CS with proteins of human proteome have been analysed. The search using NCBI PROTEIN, EMBL, UNIPROT, Human Proteome Map (HPM), BIOCYC-HUMAN and other databases showed that in the human proteome there are at least 120 proteins whose activity is associated with CS, of which 11 target proteins for CS were isolated by functional binding [3] (Table 1). Among these results we found that CS induces activation of the CD44 receptor and reduces the excessive activity of matrix metalloproteinase's (MMPs) via transcription regulation [5]. CS also promotes an increase in the activity of chondroitin sulfate glycosyltransferases CHPF, CSGALNACT1, CSGALNACT2 (reconstruction of the connective tissue) [6], and a decrease in the activation of NF$\kappa B$ pro-inflammatory cytokines of interleukin (IL)-1, -6, tumour necrosis factor $\alpha$ (TNF $\alpha)$ and CRP [7-13]. Most of the findings in scientific literature to explain the main mechanism of the pharmacological action of CS are represented in Figure 2. Since CS are molecules with high molecular weights (>10 kDa), they exert their effects through interaction with CD44, TLR4 and ICAM1 receptors [14] on the surface of chondrocytes. By binding to $\mathrm{CD} 44$ receptor, $\mathrm{CS}$ reduces the transcription of the NF- $\kappa \mathrm{B}$ proinflammatory signalling factor, thus blocking pro-inflammatory pathways involving ADAMTS, MMP, IL1 $\beta$ and other proteins [15]. CS can also interact with pro-inflammatory receptors: TLR4, MyD88 cytosolic adapter protein, involved in signal transmission from the toll-like receptors, as well as with TNF $\alpha$ receptor on the lymphocyte surface [16]. (Figure 2)

Table 1: Results of bioinformatic analysis of the human genome and proteome, in which the most probable target proteins for the pharmacological action of CS were found

\begin{tabular}{|c|c|c|c|}
\hline Gene & Protein & Protein Function & $\mathrm{CS}$ role in Protein \\
\hline GALNS & $\begin{array}{l}\text { N-Acetylgalactosamine 6-sulfatase } \\
\text { (chondroitinase) }\end{array}$ & $\begin{array}{l}\text { Hydrolysis of 6-sulfate groups of CS, co- } \\
\text { factor of calcium ions }\end{array}$ & Chondroitinase substrate \\
\hline CHST11 & Carbohydrate-sulfotransferase 11 & $\begin{array}{c}\text { Sulfation of the } 4 \text { th position of CS } \\
\text { N-acetylglucosamine }\end{array}$ & Sulfotransferase substrate \\
\hline CD44 & CD44 receptor & $\begin{array}{c}\text { CS / hyaluronic acid receptor, degradation } \\
\text { of CS and hyaluronan }\end{array}$ & CD44 receptor activation \\
\hline HYAL1, HYAL2 & Hyaluronidase 1, 2 & CS and hyaluronan degradation & Hyaluronidase substrate \\
\hline MMP1, MMP3 & MMP 1, 3 & $\begin{array}{l}\text { Connective tissue cartilage and ligaments } \\
\text { base deterioration }\end{array}$ & MMP1, 3 inhibitor \\
\hline MMP16 & MMP 16 & $\begin{array}{l}\text { Collagen III degradation, interaction with } \\
\text { CS }\end{array}$ & MMP16 inhibitor \\
\hline MMP24 & MMP 24 & Mediator of inflammatory hyperalgesia & MMP24 inhibitor \\
\hline CD97 & CD97 receptor & $\begin{array}{l}\text { Leukocytes activation, isoform } 1 \text { interacts } \\
\text { with CS }\end{array}$ & CD97 inhibitor \\
\hline PRG4 & Proteoglycan 4 (lubricin) & $\begin{array}{l}\text { Prevention of protein deposition from } \\
\text { synovia to cartilage }\end{array}$ & $\begin{array}{l}\text { Component for lubricin } \\
\text { synthesis }\end{array}$ \\
\hline
\end{tabular}




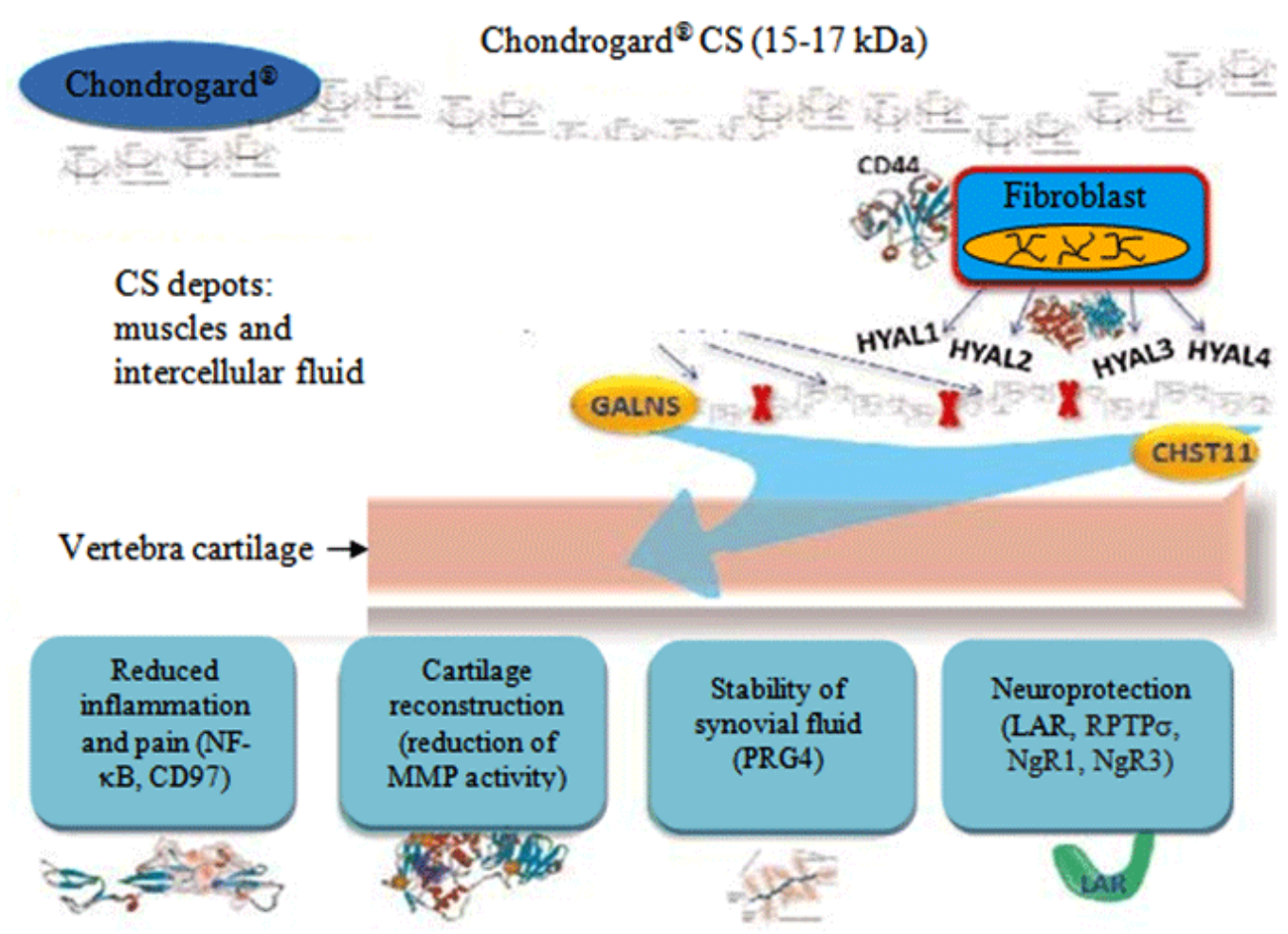

Figure 2: Efficacy of chondroitin sulfate (Chondroguard® medication) in hernias and protrusions of intervertebral discs.

CS also inhibits the synthesis of prostaglandin E and MMP in IL1 $\beta$-stimulated osteoblasts [17]. When exposed to IL1 $\beta$, an increased expression of pro-inflammatory proteins involved in the synthesis of prostaglandins (COX2, mPGES1), MMP3, MMP13, RANKL (activation of osteoblasts) has been found. CS suppresses IL1 $\beta$-induced expression of COX2 $(-62 \%, \mathrm{p}<0.001)$, mPGES1 $(-63 \%, \mathrm{p}<0.001)$, MMP3 (-39\%, p = 0.08), MMP13 $(-60 \% ; \mathrm{p}$ $<0.001)$ and RANKL $(-84 \%$; $\mathrm{p}<0.001)$ [17-18].

To study the entire set of CS effects on human cells and tissues, pharmacoproteomic studies were conducted [7, 8, 19-23], which focused on the impact of CS on the level of expression of all known proteins of human proteome. The pharmacoproteomic study of CS effects in healthy volunteers made possible to establish the optimal expression of 31 target proteins of CS, overall including increased levels of energy metabolism (31\%) and biosynthesis (13\%) proteins, as well as numerous signalling proteins (54\%) [19]. A decrease in the activity of different cytokine signalling pathways was found in healthy volunteers who were administered with CS (1200 mg / day) and GS (1500 mg / day) [8]. Downstream of these cytokines, it has been established that CS therapy prevents degradation of I $\kappa-\mathrm{B} \alpha$ subunit, thus inhibiting NF- $\kappa \mathrm{B}$ proinflammatory signal protein. Interacting with I $\kappa-\mathrm{B} \alpha$ regulators, NF- $\kappa B$ loses its ability to move to the cell nucleus and activate the expression of genes involved in the inflammatory reaction. In this report in healthy volunteers, inflammatory signalling pathways and processes regulated by CS were examined: 1) JAK/STAT (a signalling pathway modulating a wide range of cytokines and growth factors); 2) IgA synthesis in the intestine (increasing barrier immunity); 3) regulation of transendothelial leukocyte migration; 4) binding of hematopoietin/interferon receptors. THBS4, ITGA and ITGB proteins of cell adhesion (supporting the structure of connective tissue) were among the most significant proteins, the level of which significantly changes under the influence of CS + GS [8].

Another pharmacoproteomic study of chondrocytes obtained from patients with OA [20] established that the treatment of chondrocytes with CS increased the secretion of connective tissue extracellular matrix components (collagen, annexin, tenascin, and aggrecan), connective tissue growth factors (PENK, CTGF) and reduced the level of proteases, which are associated with connective tissue degradation (SERPINA3, SERPIN1). Therefore, CS is not only a "cartilage-building material", but it also potentiates the synthesis of cartilage tissue components and reduces the activity of deterioration processes of this newly formed tissue. Stimulation of IL-1 $\beta$ cells after treating chondrocytes with CS reduced the pro-inflammatory response of chondrocytes to this cytokine by reducing the activation of MMP1 and MMP3 [21].

Treating the cells with CS promoted a marked increase in the level of thrombospondin 1 (TSP1), a multifunctional glycoprotein of articular cartilage [22] and angiogenesis inhibitor [23]. Indeed, angiogenesis plays a key role in OA pathophysiology [24]. Increased TSP1 expression reduces the severity of inflammatory reactions and the formation of new vessels in this disease [25]. CS-induced increase in the TSP1 expression is an important molecular link to the CS anti-arthritic effect. 


\section{Molecular Mechanism of Action of CS in OA}

CS supports connective tissue regeneration. The mechanisms of CS's anti-arthritic effect in the articular chondrocytes and synovial fibroblasts at a concentration of 1-100 $\mu \mathrm{g} / \mathrm{mL}$ include inhibition of the expression of aggrecanase 1 / A (destroys Aggrecan proteoglycan - an important structural component of the cartilage), MMP13 (the level of which is increased by exposure to IL1 $\beta$ ) and enhance the production of TIMP3, a tissue inhibitor of MMP types $[4,5]$. In case of knee OA, both the mean concentration of CS $(12.04 \mu \mathrm{g} / \mathrm{mg}$, the norm of $14.84 \mu \mathrm{g} /$ $\mathrm{mg}, \mathrm{p}=0.021)$ and the molecular weight reflecting the average CS chain length (5.36 kDa, the norm - $6.19 \mathrm{kDa}, \mathrm{p}=0.026$ ) are reduced. Reduced expression of genes encoding chondroitin sulfate glycosyltransferases CHPF, CSGALN-ACT1, CSGALNACT2 (contributing to the reconstruction of connective tissue) was established in the affected area, and the activity of MMPs was increased showing a destructive effect on cartilage [6].

\section{Molecular Mechanisms of CS Anti-Inflammatory Effects}

CS reduces the activation of NF-KB and IL1, IL6 and CRP inflammatory biomarkers [7]. According to a study in a group of healthy volunteers with an elevated body mass index (25-32 $\mathrm{kg} / \mathrm{m}^{2}, \mathrm{n}=18,20-55$ years) the administration of CS (1200 mg / day) and GS (1500 mg / day) for 28 days resulted in a $23 \%$ reduction in the CRP level compared to the placebo group $(\mathrm{p}=$ 0.048 ) [8], and by $28-36 \%(n=220)$ according to another study [9]. In a study involving 10,000 adult healthy subjects, regular administration of CS + GS was associated with a decrease in CRP (by 20\%) [10]. The study has demonstrated that, depending on the dose, CS reduce the excessive synthesis of pro-inflammatory IL1 $\beta(p=0.003)$ and TNF- $\alpha(p=0.02)$ in the inflammation model caused by urate crystals [12].

The main molecular mechanism of CS anti-inflammatory effects is inhibition of NF- $\kappa B$ (one of the central mediators of inflammation) translocation into the nucleus. Normally, NF$\kappa \mathrm{B}$ almost does not bind to chondrocytes DNA. In the collageninduced arthritis model, NF- $\kappa \mathrm{B}$ binding to DNA increased significantly [13]. Administration of CS led to a significant inhibition of NF- $\mathrm{KB}$ binding to chondrocytes DNA.

\section{Molecular Mechanisms of CS Neuroprotective Activity}

CS proteoglycan are important modulators in the central nervous system: they influence the direction of neuronal cones growth (due to the provision of a mechanical framework in the interneuronal space), promote synapse maturation and regulate synaptic plasticity. After neuronal damage (craniocerebral trauma, spinal cord injury, etc.), the synthesis of CS in glia sharply increases with the subsequent formation of a glial scar around the lesion. The CS effects in the central nervous system happen, in particular, due to interaction with tyrosine phosphatase $\sigma$, (RPTP, participate in synaptogenesis) neuronal receptors and NgR1 and NgR3 receptors (axon regeneration) [26]. CS are necessary to regulate the differentiation of neural progenitor cells. Lack of CS in the neural plate of the embryo leads to a decrease in SOX2 expression [27].

CS show antioxidant and neuroprotective properties by activating the $\mathrm{PKC} / \mathrm{PI} 3 \mathrm{~K} /$ Akt signalling pathway, resulting in an increase in the level of hemoxygenase 1 antioxidant enzyme and suppression of caspase 3 activation. The disaccharides of $\mathrm{N}$-acetyl glucosamine and glucuronic acid, which are formed during the CS metabolism, also have neuroprotective properties $[28,29]$. The neuroprotective effect of CS on neurons in the area of the hernia projection promotes a gradual decrease in the level of pro-inflammatory cytokines in CSF (gradually, since the full CSF turnover takes up to 7 days). With spine osteochondrosis and spinal disc hernias, an increase in CSF pressure on the nerve tissue may occur. If the connective tissue in the area of hernia weakens, the connective tissue membranes of the spinal cord stretch, which increases the secretion of pro-inflammatory cytokines and aggravates the pain syndrome. The patient may experience not only back pain associated with increased pressure in the vertebral canal, but also paraesthesia, hyperesthesia in the compression zone of the spinal nerves. The spinal nerve consists of two roots: front (motor) and rear (sensitive). The roots are connected in the intervertebral foramen, i.e., in the immediate vicinity of the hernia. In addition, when leaving the intervertebral foramen, the hernia presses not only the roots, but also the socalled meningeal branch leading to connective tissue membranes of the spinal cord. When the hernia presses on the roots and meningeal branch, the pain symptoms grow not only segmentally in the area of the hernia, but also along the entire spine. As a result, axonal transport, synaptogenesis worsen and a pro-inflammatory shift of the CSF cytokine profile towards inflammation is noted. The anti-inflammatory effect of CS, mediated by the inhibition of NF- $\kappa B$ translocation into the nucleus, significantly reduces the synthesis of pro-inflammatory cytokines. The ability of CS to exert neuroprotective effects through the support of NgR1 and NgR3 reticulon-receptor function creates conditions for the regeneration of axons of the spinal roots and the meningeal branch [26]. Entering the meningeal branch, CS suppresses proinflammatory reactions. In addition, $\mathrm{N}$-acetyl glucosamine and glucuronic acid disaccharides, which are produced during the CS metabolism, enter the CSF, which also has a neuroprotective effect [29].

\section{CS-Based Commercial Therapies}

The available data from fundamental and clinical studies indicate significant differences in the efficacy and safety of various CS-based medications [30-38]. The pharmacological quality of CS is very important, since taking large doses of insufficiently purified CS can contribute to the development of adverse effects (increased transaminase levels, acute liver damage as in autoimmune hepatitis [39], a change in the level of pro-inflammatory factors [30], etc.).

A comparative pharmacoproteomic study was carried out using three different CS medications (CS1, CS2, and CS3) at the same dose $(200 \mu \mathrm{g} / \mathrm{ml})$ which were used to treat chondrocytes in OA patients [30]. CS1 medication (obtained from porcine 
cartilage, $90.4 \%$ purification rate) increased the level of mitochondrial superoxide dismutase, extracellular cartilage matrix proteins, oligomeric protein matrices, but at the same time the concentration of some pro-inflammatory factors (stromelysin 1). Safer options included CS2 medications (obtained from bovine trachea, $96.2 \%$ purification rate) and CS3 medications (obtained from bovine trachea, $99.9 \%$ purification rate; this CS is used to manufacture Chondroguard $\AA$ medication), which also increased the number of structural proteins of the connective tissue matrix and growth factors, but did not increase the level of pro-inflammatory proteins [30].

Differences in the properties of CS-based medications are attributable both to the degree of purification and to the differences in the chemical composition of CS extracts. CS blends are extracted from animal and fish cartilage, therefore, like many other natural extracts, have a wide range of molecular weights, a different amount and form of CS chains sulfation. In various samples of medications, the total content of CS is $90-99 \%$, chondroitin-4-sulfate is $62-78 \%$, and chondroitin-6-sulfate is 15 $31 \%$.

Only pharmaceutical grade CS should be used for treating OA patients: a high degree of purification and standardized sulfation allows avoiding the pro-inflammatory reactions caused by impurities in the natural extract [31]. On the contrary, the quality of the CS molecules for nutraceutical needs (for oral administration) can be very low [32,33]. For example, the study of a number of dietary supplements available on the EU market demonstrated that the declared content of CS was observed only in 4 out of 10 samples. In 4 dietary supplements, the CS content was actually $0-1 \%$, while their labels indicated much higher content of $47 \%, 17 \%, 12 \%$ and $6 \%$. Only $30-45 \%$ of the declared CS content was found in one sample, and only in three samples did it correspond to that indicated on the label [32]. Thus, CSbased medications should be strictly controlled in terms of CS excipient standardization.

The study of disaccharides, which are part of the CS molecule, also allows to determine the origin of CS. Differences between CS of various origins are evident on chromatograms: they have different charge densities (the number of sulfate groups per one disaccharide fragment) and the 4-sulfated/6-sulfated CS ratio (the ratio between the amounts of sulfated groups located at positions 4 and 6 on the CS). Molecular weight of CS is important for pharmacological activity, since overly fragmented CS $(n=1,2)$ may not have the desired biological effects $[31,32]$. Bioavailability of CS of various origins depends largely on their molecular weight, charge density and sulfation. A pharmacokinetic study showed that a decrease in the relative amount of unsulfated CS disaccharides was noted after oral administration of CS. At the same time, the level of the 4-sulfated disaccharide increases to a maximum (52 $\pm 25 \%$ ) after 6 hours, and 6 -sulfated and disulfated disaccharides - after 10 hours. It was found that 4-sulfated CS is first absorbed before 6-sulfated CS [34]. Scintigraphic analysis has showed that CS exhibits tropism to the cartilaginous tissues, and oligosaccharides appear in the blood resulting from the enzymatic hydrolysis of CS [35-38]. High-purity CS does not have a side effect on the gastrointestinal tract, clotting and kidney function [40]. Therefore CS-based medications have a multifaceted anti-inflammatory effect. CS are not just a "building material" for cartilage, but CS improve the synthesis of connective tissue components in the cartilage, reducing the activity of the degradation processes of this newly formed tissue. Highly purified pharmaceutical CS of standardized sulfation are not only efficient to treat $\mathrm{OA}$, but also devoid of side effects.

\section{Pharmacological Analysis of Chondroguard $\AA$ Composition}

Chondroguard $®$ is intended for intramuscular (i.m.) administration for the treatment of arthritis and osteochondrosis. As the active ingredient, it contains $100 \mathrm{mg}$ of highly purified pharmaceutical CS from bovine trachea (99.9\% purification rate) in the form of sodium salt. CS has been stabilized using standard components - benzyl alcohol ( $9 \mathrm{mg}$ ) and sodium metabisulfite antioxidant (1 $\mathrm{mg}$ ). During manufacturing the $\mathrm{pH}$ of the solution is adjusted to values close to neutral (6.0-7.5), using an alkali solution (sodium hydroxide). Benzyl alcohol serves as a stabilizer in many injection medications [41]. LD50 of benzyl alcohol in the acute toxicity test in rats is $1200 \mathrm{mg} / \mathrm{kg}$, which corresponds to Class III toxicity ("moderately hazardous" substances according to 12.1.007-76 Harmful substances GOST). Benzyl alcohol is rapidly metabolized to an even less toxic benzoic acid (LD50 $1700-3700 \mathrm{mg} / \mathrm{kg}$ ), then conjugated with glycine in liver and excreted as hippuric acid [42]. Thus, the Chondroguard $\AA$ solution does not contain toxic components, but includes only substances that ensure the safety of the active ingredient CS. It is important to note that, the amino acid L-proline is not used as a stabilizer in Chondroguard $\AA$, since its parenteral administration can cause adverse events in the CNS (memory impairment [43], cognitive deficits [44], changes in the neurotransmitter balance [45, 46]).

The active principle of Chondroguard ${ }^{\circledR}$ is highly purified chondroitin sulfate (CS-BIOACTIVEC) by Bioiberica S.A.U. (Barcelona, Spain) Ph. Eur. Certificate, obtained from bovine trachea, which meets the requirements of the European Pharmacopoeia. The efficacy and safety of drugs based on this specific raw material was confirmed in 25 international clinical trials involving more than 5,000 patients. This molecule has a number of features that are very important for the implementation of chondroprotective and other effects of CS. CS extract from bovine trachea is characterized by a narrow range of molecular weight (14-26 kDa) and on average contains about $60 \%$ of chondroitin-4-sulfate and $30 \%$ of chondroitin-6sulfate $[31,47]$. Such low-tolerance indicators of the CS natural extract from bovine trachea composition enable significant improvement of the quality of standardization of the obtained CS pharmaceutical final product, characterized by an average molecular mass of 15-17 kDa (corresponding to $\mathrm{n}=29-35$; see Fig.1) used in Chondroguard®. 


\section{Mechanisms of Action of the Pharmaceutical Chondroitin Sulfate CS-BIOACTIVE@) (Bioiberica S.A.U.)}

In spinal hernias treatment, there is a positive experience of Chondroguard $®$ paravertebral injection, i.e., directly into the projection area of the intervertebral disc, affected by hernia [48]. With the i.m. administration, the maximum concentration of CS in the blood plasma is achieved after 1 hour, and then gradually decreases within 48 hours. The experiment shows those 15 minutes after the i.m. injection, CS is found in the synovial fluid, and then enters the cartilage, where the maximum drug concentration is observed 48 hours later [48].

The described features of CS-BIOACTIVE@ contribute to the formation of a more stable CS depot in the area of vertebral lesion. As noted above, in health the molecular mass of cartilage CS is $6.19 \mathrm{kDa}(\mathrm{n} \sim 12)$ on average and decreases with its pathological changes (for example, at $\mathrm{OA}$ it goes up to $5.36 \mathrm{kD}$, $\mathrm{n} \sim 10$ ) [6]. At the same time, when Chondroguard $®$ is injected, longer chains of CS (15-17 $\mathrm{kDa}, \mathrm{n}=29-35)$ enter the muscle, which are unable to penetrate the cell membrane because of their large size and form a depot in the intercellular fluid of the muscle. Then these long CS chains on exposure to special enzymes are converted into shorter chains (oligosaccharides) that can penetrate into the chondrocytes in the herniated area. They serve as a "building material" for reconstructing the cartilage and ligaments, exhibiting anti-inflammatory properties, entering the synovial fluid of the vertebral joint, CSF, and others. Due to the lack of blood supply, intervertebral disc nutrition is due to the diffusion of nutrients from the intercellular fluid. The results of bio informational analysis of the human genome and proteomes shown above (see Table 1) allow us to extend these mechanisms of CS pharmacological action to the level of specific target proteins. Situated in the extracellular fluid of the muscle, long chains of CS activate CD44 receptor on the chondrocytes membrane (since CD44 protein is a receptor for CS and for the short chain SC oligosaccharides) [49]. When CS interacts with CD44 receptor, this activates degradation processes of oligosaccharide chains in the CS depot, cartilage reconstruction $[49,50]$, and reduction of chronic inflammation because of inhibition of NF-B proinflammatory signalling pathway. The binding of CS with the CD44 receptor primarily enhances the activity of hyaluronidases (HYAL1, HYAL2, HYAL3, HYAL4), which ensure the processing of CS chains in the muscle depot into shorter oligosaccharides [51]. Despite its name, hyaluronidases enzymes hydrolyse not only hyaluronic acid but also CS. Hydrolysis of long chains of CS occurs at random positions of the polymer chain $(1 \rightarrow 4$ linkages between $\mathrm{N}$-acetyl glucosamine and D-glucuronic acid, activity of EC 3.2.1.35 in the International Enzyme Nomenclature, with the formation of shorter oligosaccharides ending in $\mathrm{N}$-acetyl glucosamine residue). Then, the oligosaccharides decompose into even smaller fragments, down to individual $\mathrm{N}$-acetyl glucosamine and D-glucuronic acid molecules [51]. In general, hyaluronidases reduce the viscosity of CS aqueous solution in the depot and increase the amount of CS oligosaccharide chains entering the chondrocytes [52]. For the hydrolysis of long chains of CS with hyaluronidases, the sulfation features of CS are very important. First, hyaluronidases hydrolyse primarily chondroitin-4-sulfate [53], the content of which is $60 \%$ in the CS-BIOACTIVE@. Secondly, chondroitin-6-sulfate $30 \%$ of the composition of the product) promotes the diversification of oligosaccharide chains formed on exposure of CS to hyaluronidases. For example, hyaluronidases convert chondroitin-4-sulfate into a mixture of tri- and pentasaccharides, and chondroitin-6-sulfate into a mixture of penta- and heptasaccharides [54]. Additionally, the absorption of chondroitin-4-sulfate is faster, while chondroitin6 -sulfate absorbs more slowly [34]. Therefore, the use of 60/30 $\%$ ratio of chondroitin-4-sulfate to chondroitin-6-sulfate allows regulating the content of CS in the blood, maintaining the desired concentration for a long time (more than 10 hours).

Other target proteins of the human proteome are also important for the processing of the muscular CS depot (Table $2)$. For instance, GALNS (N-acetylgalactosamine-6-sulfatase) chondroitinase removes sulfate groups of chondroitin-6-sulfate, thereby making CS more susceptible to subsequent degradation by hyaluronidases [49].

Table 2: Parameters of CS molecular weight, according to different sources [34-36].

\begin{tabular}{|c|c|c|c|c|c|}
\hline Parameter & Bovine CS & Porcine CS & Avian CS & Shark CS & Fish CS \\
\hline \multicolumn{6}{|l|}{ Molecular weight, kDa } \\
\hline $\mathrm{Mn}$ & $10.0-15.0$ & $9.0-13.0$ & $7.8-12.8$ & $20.5-26.0$ & $27.0-34.0$ \\
\hline Mw & $20.0-26.0$ & $13.7-18.7$ & $15.6-20.6$ & $64.2-70.2$ & $50.0-60.0$ \\
\hline Dispersion $(\mathrm{Mn} / \mathrm{Mw})$ & $1.80-2.20$ & $1.35-1.65$ & $1.60-2.00$ & $2.50-3.10$ & $1.50-2.50$ \\
\hline \multicolumn{6}{|l|}{ Disaccharides } \\
\hline$\Delta \mathrm{Di}-0 \mathrm{~s}$ & 6.0 & 6.0 & 8.0 & 3.0 & 3.0 \\
\hline$\Delta \mathrm{Di}-6 \mathrm{~s}$ & 33.0 & 14.0 & 20.0 & 50.0 & 39.0 \\
\hline$\Delta \mathrm{Di}-4 \mathrm{~s}$ & 61.0 & 80.0 & 72.0 & 29.0 & 43.0 \\
\hline$\Delta \mathrm{Di}-2,6$ dis & $\mathrm{n} / \mathrm{a}$ & $\mathrm{n} / \mathrm{a}$ & $\mathrm{n} / \mathrm{a}$ & 15.0 & 13.0 \\
\hline$\Delta \mathrm{Di}-4,6$ dis & $\mathrm{n} / \mathrm{a}$ & $\mathrm{n} / \mathrm{a}$ & $\mathrm{n} / \mathrm{a}$ & 2.0 & 1.0 \\
\hline$\Delta \mathrm{Di}-2,4 \mathrm{dis}$ & $\mathrm{n} / \mathrm{a}$ & $\mathrm{n} / \mathrm{a}$ & $\mathrm{n} / \mathrm{a}$ & 1.0 & 1.0 \\
\hline $\mathrm{R}$ & $0.90-0.96$ & $0.92-0.96$ & $0.90-0.94$ & $1.10-1.20$ & $1.08-1.16$ \\
\hline
\end{tabular}

Note. $\mathrm{Mn}$-average molecular weight in accordance with the number of disaccharide units (n); Mw - average molecular weight; $\Delta \Delta$ Di-0s - percentage of non-sulfated disaccharides; $\Delta \mathrm{Di}-6 \mathrm{~s}$ - percentage of 6-sulfated disaccharides; $\Delta \mathrm{Di}-4 \mathrm{~s}$ - percentage of 4-sulfated disaccharides, etc.; $\mathrm{R}$ - charge density (number of sulfate groups per disaccharide unit); $4 \mathrm{~s}: 6 \mathrm{~s}$ - the ratio between 6-sulfated and 4-sulfated disaccharides; n/a - no data available

Citation: Lila AM, Gromova OA, Torshin IY, Montell E (2018) Molecular Effects of Chondroitin Sulfate in Osteoarthritis and Herniated 
Carbohydrate-sulfotransferase CHST11, on the contrary, sulfates CS forming chondroitin-4-sulfate. CS oligosaccharides formed by the action of hyaluronidases diffuse in the intercellular fluid into the hernia lesion zone and inhibit MMP1, MMP3 (the excess activity of which degrades the connective-tissue cartilage base), MMP16 (degrades collagen type III), and MMP24 (inflammatory hyperalgesia mediator) and others. Different types of MMPs digest most of the components of the extracellular matrix $[55,56]$. In the human genome, there are at least 25 MMP genes. Excess of MMP activity is associated with chronic inflammation (arthritis, atherosclerosis, tumour diseases, etc.) [57]. Virtually all MMPs are characterized by a very similar fullatom structure of individual protein molecules; each molecule of the enzyme in all cases includes four calcium ions and two zinc ions. Note that the decrease in MMP1, MMP3 activity observed in CS pharmacoproteomic studies [21] corresponds to the antitumor effect of CS established in large-scale clinical epidemiological studies [58].

Oligosaccharides of CS interact with CD97 receptor, which prevents excessive activation of leukocytes in the cartilage, muscles and synovial fluid. The CS oligosaccharides are also necessary for the synthesis of PRG4, which prevents the pathological precipitation of proteins from the synovial fluid on the cartilage surface, i.e. stabilizes the state of the synovial fluid. An important anatomical feature of intervertebral hernias is their direct proximity to the spinal cord. Consequently, the entrapment of spinal nerves by hernia protrusion leads to a pronounced pain syndrome. The oligosaccharides that form in CS and diffuse in the intercellular fluid, reach the ends of the vertebral nerve strangulated by a hernia. Absorbed into neurons, the CS oligosaccharides have an anti-inflammatory and analgesic effect, and acting on RPTP $\sigma$ neuronal receptors (involved in synaptogenesis) and NgR1 and NgR3 reticulon-receptors (regeneration of the axon) [26], exhibit neuroprotective action on the strangulated spinal nerve.

The importance of the optimal length of CS chain should be further emphasized. If the CS chains are too short (as in the case of porcine CS, see Table 2 [34-36]), the CS depot in the intercellular fluid would be consumed too quickly, and this would lead to oligosaccharide dispersion and the lack of proper impact on chondrocytes. In case of too long, CS chains (as in the case of avian or fish CS), the injected CS solution would be too viscous, which would not only slow the processing of CS into oligosaccharides, but also stimulate numerous adverse events already at the stage of i.m. administration.

Pharmacoproteomic study of CS-BIOACTIVE@ demonstrated that CS causes changes in the secretion of more than 36 of the 186 proteins of the extracellular matrix of the cartilage, including an increase in the level of the TSP1 protein that supports the structure of the articular cartilage [20]. It has been confirmed in vitro that this CS inhibits the activity of NF-B in macrophages activated by lipopolysaccharide $[59,60]$, and reduce the synthesis of MMP3 and MMP1 [61]. In addition, this CS affects the AMPA and kainate receptors of hippocampal neurons, causing cell depolarization, signalling intracellular "waves" of calcium ions, and exhibits an analgesic effect [62].

\section{Experimental Results And Clinical Trials Using CS-BIOACTIVE@ (Bioiberica S.A.U.)}

CS-BIOACTIVE@ has been extensively studied in OA models and OA patients. In the OA knee model in rats, the administration of CS (140 mg / kg CS, $175 \mathrm{mg} / \mathrm{kg} \mathrm{GxS}$ ) reduced cartilage degradation and the level of pro-inflammatory markers IL1 $\beta$ and TNF $\alpha$, inflammation biomarkers in serum, MMP3, C-terminal telopeptide of type II collagen and NF- $\mathrm{BB}$ [63].

A number of clinical trials performed with CS-BIOACTIVEC substance-based medicines have been conducted [64-66]. It has been demonstrated that the efficacy of the treatment with oral administration of CS (1200 mg/day, orally, 24 months) in patients with $\mathrm{OA}$ of knee joints was comparable to that of nonsteroidal anti-inflammatory celecoxib (200 mg/day, $\mathrm{n}=62$ ). The action of CS-BIOACTIVE@ was associated with a decrease in the activity of MMP1 and MMP3 [64], and with reduced levels of biomarkers of inflammation (soluble collagen type 2, Coll2-1) in blood serum [65]. In addition, the use of CS-BIOACTIVE@ is promising to treat various inflammatory processes that are comorbid with diseases accompanied by damage to the cartilaginous tissue [67-71].

Some investigators have conducted a number of studies that demonstrated the efficacy and safety of i.m. Chondroguard ${ }^{\circledR}$ administration. A study of Chondroguard $®$ efficacy in patients with knee OA ( $\mathrm{n}=422$, II-III Kallgren-Lawrence stage) with a 2-yr i.m. administration demonstrated a significant improvement in such efficacy parameters as the WOMAC scale and the time spent by the patient to walk a distance of 15 meters [72]. Significant improvement upon Chondroguard $₫$ administration can be observed in a shorter period (1-2 months) [73]. With i.m. administration of the drug, the results of treatment persist longer than with oral administration [74].

\section{The Use of Chondroguard $₫$ In Intervertebral Disc Extrusions and Protrusions}

A promising area for the use of drugs based on CSBIOACTIVE@ is the therapy of spinal disc hernias and protrusions, which includes both paravertebral administration [48] and oral administration [75]. In a study of Gutyansky et al [48] it has been demonstrated that CS paravertebral injection in dorsalgia cases leads to a decrease in the soreness of the paravertebral points on palpation, expansion of the motor regimen, and reduced severity of the stretch symptoms on Day 3-4. On Day 20-21 there is a significant normalization of the muscle tone, a significant increase in the range of motion in the lumbar-sacral region and almost full resolution of the stretch symptoms [48]. With paravertebral administration of CS, not only more advanced resolution of the pain syndrome was registered, but also significant structural changes in the intervertebral disk (according to the results of magnetic resonance imaging): hernia size reduced by $0.5-2 \mathrm{~mm}$ and intervertebral disk protrusion reduced by $1-2 \mathrm{~mm}$ in $67 \%$ of the patients, a significant increase in disc height was achieved in $71 \%$ of the patients [48].

\section{Conclusions}

Following a bioinformatic analysis of human proteome 
interactions with chondroactive proteins and the current knowledge about the molecular mechanisms of CS activity, this review has highlighted a molecular and pharmacological concept regarding to the effect of Chondroguard $\AA$ in $\mathrm{OA}$, hernias, as well as protrusions of the intervertebral disc. Paravertebral injection of Chondroguard $\AA$ provides a CS depot in the intercellular space of the muscle in the immediate vicinity of the connective tissue lesion in the vertebral joint. CS chains interact with CD44 receptor on the surface of muscle fibroblasts, which, on one hand, inhibits inflammation due to inactivation of the NF- $\kappa$ B pro-inflammatory factor, and, on the other hand, promotes an increase in the activity of hyaluronidases enzymes that break down CS chains into shorter oligosaccharide fragments. The optimal length of CS chains in Chondroguard ${ }^{\circledR}$ provides a slow release of short oligosaccharides exhibiting chondroprotective activity.

Short oligosaccharide fragments propagate through the intercellular fluid of the muscle and enter ligaments, cartilage lesion and synovial fluid. Oligosaccharides reach chondrocytes, where they activate $\mathrm{CD} 44$ receptor on the surface which is followed by inactivation of NF- $\mathrm{BB}$ pro-inflammatory factor in the cartilage tissue and the start of the connective tissue reconstruction programme. In this situation, chondrocytes begin to use the CS oligosaccharides also as a "building material" for the synthesis of the gel base of the cartilage connective tissue. In addition, oligosaccharides inhibit MMP1, MMP3 (their excess activity destroys the cartilage connective tissue base), MMP16 (causes collagen type III degradation) and MMP24 (an inflammatory hyperalgesia mediator).

In addition, CS oligosaccharides interact with CD97 receptor (which prevents excessive activation of leukocytes in the cartilage, muscles and synovial fluid). CS oligosaccharides are also necessary for the synthesis of PRG4, which stabilizes the state of the synovial fluid. Then, oligosaccharides from CS diffuse in the intercellular fluid, where they reach the endings of the vertebral nerve pinched by hernia. Absorbed from the intercellular fluid into the neurons of the vertebral nerves, CS oligosaccharides have an anti-inflammatory, analgesic effect and provide neuroprotection (due to the effect on the neuronal receptors LAR, RPTP $\sigma, N g R 1$ and NgR3). This way oligosaccharides formed during the biotransformation of CS from Chondroguard $\AA$ during parenteral, including paravertebral, administration affect the inflammation, the regeneration of the connective tissue, the composition of the synovial fluid, and provide neuroprotection of the vertebral nerves. These effects of Chondroguard ${ }^{\circledR}$ contribute not only to the reduction of OA symptoms, but also to the morphological restoration of the herniated lesion.

\section{Author Contributions}

The research was carried out with the support of Sotex LLC. The authors bear full responsibility for providing the final version of the manuscript for printing. All authors took part in developing the concept of the article and writing the manuscript. The final version of the manuscript was approved by all authors.

\section{Conflicts of Interest}

None declared

\section{References}

1. Yudina NV, Gromova OA, Torshin IYu, et al. Degenerative diseases of the intervertebral disc as a manifestation of connec- tive tissue dysplasia: study of microelement composition of herniated discs and therapeutic effects of the drug Magnerot ${ }^{\circledR}$. Farmateka. 2010; (1):112-8. (In Russ.)

2. Fardellone P, Zaim M, Saurel AS, Maheu E. Comparative efficacy and safety study of two chondroitin sulfate preparations from different origin (avian and bovine) in symptomatic osteoarthritis of the knee. Open Rheumatol J. 2013; 7:1-12. DOI:10.2174/18743129013070100 01

3. Torshin IYu. Sensing the change from molec- ular genetics to personalized medicine. New- York: Nova Biomedical Books; 2009.

4. Imada K, Oka H, Kawasaki D, Miura N, Sato T, Ito A. Anti- arthritic action mechanisms of natural chon- droitin sulfate in human articular chondrocytes and synovial fibroblasts. Biol Pharm Bull.2010; 33(3):410-414.

5. Campo GM, Avenoso A, Campo S, D’Ascola A, Ferlazzo AM, Samà $D$, et al. Purified human chondroitin-4-sulfate reduced MMP/ TIMP imbalance induced by iron plus ascorbate in human fibroblast cultures. Cell Biol Int. 2006; 30(1):21-30. DOI:10.1016/j. cellbi.2005.08.009

6. Ishimaru D, Sugiura N, Akiyama H, Watanabe H, Matsumoto K. Alterations in the chondroitin sulfate chain inhuman osteoarthritic cartilage of the knee. Osteoarthritis Cartilage. 2014; 22(2):250-258. DOI: 10.1016/j.joca.2013.11.010.

7. Volpi N. Anti-inflammatory activity of chon- droitin sulfate: new functions from an old nat- ural macromolecule. Inflammopharmacology. 2011; 19(6):299-306. DOI: 10.1007/ s10787-011-0098-0.

8. Navarro SL, White E, Kantor ED, Zhang Y, Rho J, Song X, et al. Randomized trial of glucosamine and chon- droitin supplementation on inflammation and oxidative stress biomarkers and plasma pro- teomics profiles in healthy humans. PLoS One. 2015; 10(2):e0117534. DOI:10.1371/journal.pone.0117534

9. Kantor ED, Lampe JW, Navarro SL, Song X, Milne GL, White E. Associations between glucosamine and chon- droitin supplement use and biomarkers of sys- temic inflammation. JAltern Complement Med. 2014; 20(6):479-485. DOI:10.1089/acm.2013.0323.

10. Kantor ED, Lampe JW, Vaughan TL, Peters U, Rehm CD, White E. Association between use of spe- cialty dietary supplements and C-reactive protein concentra- tions. Am J Epidemiol. 2012; 176(11): 1002-1013. DOI: 10.1093/aje/kws186.

11. Kim MM, Mendis E, Rajapakse N, Kim SK. Glucosamine sulfate promotes osteoblastic differentiation of MG-63 cells via antiinflam- matory effect. Bioorg Med Chem Lett. 2007; 17(7):19381942. DOI:10.1016/j.bmcl.2007.01.030

12. Orlowsky EW, Stabler TV, Montell E, Vergés J, Kraus VB. Monosodium urate crystal induced macrophage inflammation is attenuated by chondroitin sul- phate: pre-clinical model for gout prophylaxis? BMC Musculoskelet Disord. 2014; 15:318. DOI: 10.1186/1471-247415-318.

13. Campo GM, Avenoso A, Campo S, D’Ascola A, Traina P, Calatroni A. Chondroitin-4-sulfate inhibits NF-kB translocation and caspase 
activation in colla- gen-induced arthritis in mice. Osteoarthritis Cartilage. 2008; 16(12):1474-1483.DOI:10.1016/j.joca.2008.04.002.

14. Lo YL, Sung KH, Chiu CC, Wang LF. Chemically conjugating polyethylenimine with chondroitin sulfate to promote CD44mediated endocytosis for gene delivery. Mol Pharm. 2013; 10(2):664-676. DOI: 10.1021/mp300432s.

15.Legendre F, Baugé C, Roche R, Saurel AS, Pujol JP. Chondroitin sulfate modulation of matrix and inflammatory gene expression in IL-1beta-stimulated chondrocytes - study in hypoxic alginate bead cultures. Osteoarthritis Cartilage. 2008; 16(1):105-114.

16. Campo GM, Avenoso A, Campo S, Traina P, D'Ascola A, Calatroni A. Glycosaminoglycans reduced inflammatory response by modulating toll-like receptor-4 in LPS-stimulated chondrocytes. Arch Biochem Biophys. 2009; 491(1-2):7-15. DOI: 10.1016/ j.abb.2009.09.017

17. Pecchi E, Priam S, Mladenovic Z, Gosset M, Saurel AS, Aguilar L, et al. A potential role of chondroitin sulfate on bone in osteoarthritis: inhibition of prostaglandin $\mathrm{E}(2)$ and matrix metalloproteinases synthesis in interleukin-1beta-stimulated osteoblasts. Osteoarthritis Cartilage. 2012; 20(2):127-135. DOI: 10.1016/j. joca.2011.12.002.

18. Rovati LC, Girolami F, Persiani S. Crystalline glucosamine sulfate in the management of knee osteoarthritis: efficacy, safety, and pharmacokinetic properties. Ther Adv Musculoskelet Dis. 2012; 4(3):167-180. DOI: 10.1177/1759720X12437753

19. Calamia V, Ruiz-Romero C, Rocha B, Fernández-Puente $P$, Mateos J, Montell E, et al. Pharmacoproteomic study of the effects of chondroitin and glucosamine sulfate on human articular chondrocytes. Arthritis Res Ther. 2010; 12(4): R138. DOI: 10.1186/ ar3077.

20.Calamia V, Mateos J, Fernández-Puente P, Lourido L, Rocha B, Fernández-Costa $\mathrm{C}$, et al. A pharmacoproteomic study confirms the synergistic effect of chondroitin sulfate and glucosamine. Sci Rep. 2014; 4:5069. DOI: 10.1038/srep 05069.

21. Calamia V, Lourido L, Fernández-Puente $\mathrm{P}$, Mateos J, Rocha B, Montell E, et al. Secretome analysis of chondroitin sulfate- treated chondrocytes reveals anti-angiogenic, anti-inflammatory and anticatabolic proper- ties. Arthritis Res Ther. 2012; 14(5):R202. DOI: 10.1186/ar4040

22. Miller RR, McDevitt CA. Thrombospondin is present in articular cartilage and is synthe- sized by articular chondrocytes. Biochem Biophys Res Commun. 1988; 153(2):708-714.

23.Bornstein P. Thrombospondins function as regulators of angiogenesis. J Cell Commun Signal. 2009; 3(3-4):189-200. DOI: 10.1007/ s12079-009-0060-8.

24. Haywood L, McWilliams DF, Pearson CI, Gill SE, Ganesan A, Wilson D, et al. Inflammation and angiogenesis in osteoarthritis. Arthritis Rheum. 2003; 48(8): 2173-2177. DOI:10.1002/art.11094

25.Hsieh JL, Shen PC, Shiau AL, Jou IM, Lee CH, Wang CR, et al. Intraarticular gene transfer of thrombospondin- 1 suppresses the disease progression of experimental osteoarthritis. J Orthop Res. 2010; 28(10):1300-1306. DOI: 10.1002/jor.21134.

26. Dyck SM, Karimi-Abdolrezaee S. Chondroitin sulfate proteoglycans: Key modu- lators in the developing and pathologic central nervous system. Exp Neurol. 2015; 269:169- 187. DOI: 10.1016/j. expneurol.2015.04.006
27. Canning DR, Brelsford NR, Lovett NW. Chondroitin sulfate effects on neural stem cell differentiation. In Vitro Cell Dev Biol Anim. 2016; 52(1):35-44. DOI: 10.1007/s11626-015- 9941-8

28.Egea J, García AG, Verges J, Montell E, López MG. Antioxidant, antiinflammatory and neuropro- tective actions of chondroitin sulfate and proteoglycans. Osteoarthritis Cartilage. 2010; $18 \mathrm{Suppl}$ 1:S24-277. DOI: 10.1016/j.joca.2010.01.016

29. Cañas N, Gorina R, Planas AM, Vergés J, Montell E, García AG, et al. Chondroitin sulfate inhibits lipopolysaccharide- induced inflammation in rat astrocytes by pre- venting nuclear factor kappa B activation. Neuroscience. 2010; 167(3):872-879. DOI: 10.1016/j. neuroscience.2010.02.069

30.Calamia V, Fernandez-Puente P, Mateos J, Lourido L, Rocha B, Montell E, et al. Pharmacoproteomic study of three differ- ent chondroitin sulfate compounds on intracel- lular and extracellular human chondrocyte pro- teomes. Mol Cell Proteomics. 2012; 11(6): M111.013417. DOI: 10.1074/mcp.M111.013417

31. Martel-Pelletier J, Farran A, Montell E, Vergés J, Pelletier JP. Discrepancies in composition and biologi- cal effects of different formulations of chondroitin sulfate. Molecules. 2015; 20(3):42774289. DOI: $10.3390 /$ molecules20034277.

32.Volpi N. Quality of different chondroitin sulfate preparations in relation to their therapeutic activity. J Pharm Pharmacol. 2009; 61(10):1271-1280. DOI: $10.1211 / \mathrm{jpp} / 61.10 .0002$.

33. Rainsford KD. Importance of pharmaceutical composition and evidence from clinical tri- als and pharmacological studies in determining effectiveness of chondroitin sulfate and other glycosaminoglycans: a critique. J Pharm Pharmacol. 2009; 61(10):1263-1270. DOI: 10.1211/jpp/61.10.0001

34.Volpi N. Oral absorption and bioavailability of ichthyic origin chondroitin sulfate in healthy male volunteers. Osteoarthritis Cartilage. 2003; 11(6):433-441.

35.Sobal G, Dorotka R, Menzel J,Sinzinger H. Uptake studies with chondrotropic $99 \mathrm{mTc}$-chondroitin sulfate in articular cartilage. Implications for imaging osteoarthritis in the knee. Nucl Med Biol. 2013; 40(8):1013-1017. DOI: 10.1016/j.nucmedbio.2013.07.007.

36.Volpi N. Oral bioavailability of chondroitin sulfate (Condrosulf) and its constituents in healthy male volunteers. Osteoarthritis Cartilage. 2002; 10(10):768-777

37. Persiani S, Roda E, Rovati LC, Locatelli M, Giacovelli G, Roda A. Glucosamine oral bioavailability and plasma pharmacokinetics after increasing doses of crys- talline glucosamine sulfate in man. Osteoarthritis Cartilage. 2005; 13(12):1041-1049

38.Craciunescu 0, Moldovan L, Moisei M, Trif M. Liposomal formulation of chondroitin sulfate enhances its antioxidant and antiinflammatory potential in L929 fibroblast cell line. J Liposome Res. 2013; 23(2):145-153. DOI: 10.3109/08982104.2013.770016.

39. Von Felden J, Montani M, Kessebohm K, Stickel F. Drug-induced acute liver injury mim- icking autoimmune hepatitis after intake of dietary supplements containing glucosamine and chondroitin sulfate. Int J Clin Pharmacol Ther. 2013; 51(3):219-223. DOI: 10.5414/ CP201835.

40.Ronca F, Palmieri L, Panicucci P, Ronca G. Anti-inflammatory activity of chondroitin sul- fate. Osteoarthritis Cartilage. 1998; 6 Suppl A:14-21. 
41. The Merck Index: An Encyclopedia of Chemicals, Drugs, and Biologicals. Edition 11. Merck; 1989. 1138 p.

42.Brü hne F. Wright laine. Benzyl Alcohol. Ullmann's Encyclopedia of Industrial Chemistry. Edition 07. Wiley; 2007.

43. Cherkin A, Eckardt MJ, Gerbrandt LK. Memory: proline induces retrograde amnesia inchicks. Science. 1976; 193(4249):242-244.

44. Nadler JV, Wang A, Hakim A. Toxicity of L-proline toward rat hippocampal neurons. Brain Res. 1988; 456(1):168-172.

45. Volk DW, Gonzalez-Burgos G, Lewis DA. L-Proline, GABA Synthesis and Gamma Oscillations in Schizophrenia. Trends Neurosci. 2016; 39(12):797-798. DOI: 10.1016/j.tins.2016.10.009

46.Zipp GG, Barbosa J, Green MA, Terranova KM, Fink C, Yu XC, et al. Novel inhibitors of the high-affinity L-proline transporter as potential therapeutic agents for the treatment of cognitive disorders. Bioorg Med Chem Lett. 2014; 24(16):3886-3890. DOI: 10.1016/j.bmcl.2014.06.049

47. Burns DT, Walker MJ, Mussell C. Chondroitin Sulfate: A Critical Review of Generic and Specific Problems in Its Characterization and Determination-An Exemplar of a Material with an Unknown or Variable Composition (UVCB). J AOAC Int. 2018; 101(1):196-202. DOI: $10.5740 /$ jaoacint.17-0115

48.Gutyanskii OG, Chestnov AA. Experience of application of complex treatment of discogenic radiculopathy in athletes. Meditsinskii Sovet. 2017;(11):28-34. (In Russ.).

49. Fujimoto T, Kawashima H, Tanaka T, Hirose M, Toyama-Sorimachi $\mathrm{N}$, Matsuzawa Y, et al. CD44 binds a chondroitin sulfate proteoglycan, aggrecan. Int Immunol. 2001; 13(3):359-366.

50.Atarashi K, Kawashima H, Hirata T, Miyasaka M. Chondroitin sulfate proteoglycan, common ligand of L-selectin and CD44. Tanpakushitsu Kakusan Koso. 2002; 47(16 Suppl):2214-2220.

51. Harada H, Takahashi M. CD44-dependent intracellular and extracellular catabolism of hyaluronic acid by hyaluronidase- 1 and -2. J Biol Chem. 2007 Feb 23;282(8):5597-607

52. Meyer K, Hoffman P, Linker A. Hyaluronidases. In: Boyer PD, Lardy H, Myrback K, editors. The Enzymes. 2nd ed. Vol. 4. New York: Academic Press; 1960.

53.Silva C, Novoa-Carballal R, Reis RL, Pashkuleva I. Following the enzymatic digestion of chondroitin sulfate by a simple GPC analysis. Anal Chim Acta. 2015; 885: 207-213. DOI: 10.1016/j. aca.2015.05.034. PMID: 2623190

54.Knudson W, Gundlach MW, Schmid TM, Conrad HE. Selective hydrolysis of chondroitin sulfates by hyaluronidase. Biochemistry. 1984; 23(2): 368-375.

55.Cauwe B, Van den Steen PE, Opdenakker G. The biochemical, biological, and pathological kaleidoscope of cell surface substrates processed by matrix metalloproteinases. Crit Rev Biochem Mol Biol. 2007; 42(3): 113-185. DOI: 10.1080/10409230701340019

56. Malemud CJ. Matrix metalloproteinases (MMPs) in health and disease: an overview. Front Biosci. 2006; 11:1696-1701.

57. Shingleton WD, Hodges DJ, Brick P,Cawston TE. Collagenase: a key enzyme in col- lagen turnover. Biochem Cell Biol. 1996; 74(6): 759775.

58. Kantor ED, Lampe JW, Peters U, Shen DD, Vaughan TL, White E. Use of glucosamine and chondroitin supple- ments and risk of colorectal cancer. Cancer Causes Control. 2013; 24(6): 1137-1146. DOI: 10.1007/s10552-013-0192-2

59. Tan GK, Tabata Y. Chondroitin-6-sulfate attenuates inflammatory responses in murine macrophages via suppression of NF-kB nuclear translocation. Acta Biomater. 2014; 10(6): 2684-2692. DOI: 10.1016/j.actbio.2014.02.025

60.Stabler TV, Huang Z, Montell E, Vergés J Kraus VB. Chondroitin sulfate inhibits NF- $\mathrm{KB}$ activity induced by interaction of pathogenic and dam- age associated molecules. Osteoarthritis Cartilage. 2017; 25(1): 166-174. DOI: 10.1016/j.joca.2016. 08.012

61. Monfort J, Nacher M, Montell E, Vila J, Verges J, Benito P. Chondroitin sulfate and hyaluronic acid (500- $730 \mathrm{kda}$ ) inhibit stromelysin-1 synthesis in human osteoarthritic chondrocytes. Drugs Exp Clin Res. 2005; 31(2): 71-76.

62. Maroto M, Fernandez-Morales JC, Padin JF, González JC, HernándezGuijo JM, Montell E. Chondroitin sulfate, a major component of the perineuronal net, elicits inward currents, cell depolarization, and calci- um transients by acting on AMPA and kainate receptors of hippocampal neurons. J Neurochem. 2013; 125(2): 205-213. DOI:10.1111/jnc.12159

63.Terencio MC, Ferrandiz ML, Carceller MC, Ruhí R, Dalmau P, Vergés J. Chondroprotective effects of the combina- tion chondroitin sulfate-glucosamine in a model of osteoarthritis induced by anterior cru- ciate ligament transection in ovariectomised rats. Biomed Pharmacother. 2016; 79: 120-128. DOI: 10.1016/j. biopha.2016.02.005

64.Pelletier JP, Raynauld JP, Beaulieu AD, Bessette L, Morin F, de BrumFernandes AJ, et al., Chondroitin sulfate efficacy versus celecoxib on knee osteoarthritis structural changes using magnetic resonance imaging: a 2-year multicentre exploratory study. Arthritis Res Ther. 2016; 18(1): 256. DOI: 10.1186/s13075-016-1149-0

65. Möller I, Gharbi M, Martinez Serrano H, Herrero Barbero M, Verges Milano J, Henrotin Y. Effect of chondroitin sulfate on soluble biomarkers of osteoarthritis: a method to ana- lyze and interpret the results from an open-label trial in unilateral knee osteoarthritis patients. BMC Musculoskelet Disord. 2016; 17(1): 416. DOI:10.1186/ s12891-016-1268-4

66. Monfort J, Pujol J, Contreras-Rodriguez 0, Llorente-Onaindia J, López-Solà M, Blanco-Hinojo L, et al., Effects of chondroitin sulfate on brain response to painful stimulation in knee osteoarthritis patients. A randomized, double-blind, placebo-controlled functional magnetic resonance imaging study. Med Clin (Barc). 2017; 148(12): 539-547. DOI : 10.1016/j.med- cli.2016.12.036

67. Segarra S, Martinez-Subiela S, Cerda-Cuellar M,Martínez-Puig D, Muñoz-Prieto A, Rodríguez-Franco F et al., Oral chondroitin sulfate and prebiotics for the treatment of canine Inflammatory Bowel Disease: a randomized, controlled clinical trial. BMC Vet Res. 2016; 12: 49. DOI: 10.1186/s12917-016-0676-x

68.Linares PM, Chaparro M, Algaba A, Román M, Moreno Arza I, Abad Santos F, et al., Effect of Chondroitin Sulfate on Pro- Inflammatory Mediators and Disease Activity in Patients with Inflammatory Bowel Disease. Digestion. 2015; 92(4): 203-210. DOI: 10.1159/ 000439522. 
69. Melgar-Lesmes P, Garcia-Polite F, Del-Rey-Puech P, Rosas E, Dreyfuss JL, Montell E, et al., Treatment with chon- droitin sulfate to modulate inflammation and atherogenesis in obesity. Atherosclerosis. 2016; 245: 82-87. DOI: 10.1016/j.atherosclerosis.2015.12.016

70.Albinana E, Gutierrez-Luengo J, Hernandez-Juarez N, Baraibar Andres M, Montell E, Vergés J, et al. Chondroitin Sulfate Induces Depression of Synaptic Transmissionand Modulation of Neuronal Plasticity in Rat Hippocampal Slices. Neural Plasticity. 2015; 2015: 463854. DOI : $10.1155 / 2015 / 463854$

71. Verges J, Montell E, Herrero M, Perna C, Cuevas J, Pérez M, etal., Clinical and histopathological improvement ofpsoriasis with oral chondroitin sulfate: a serendipitous finding. Dermatol Online J. 2005; 11(1): 31.

72.Voloshin VP, Eremin AV, Sankaranarayanan SA, et al. Study of the efficacy of Chondroguard (chondroitin sulfate) in patients with osteoarthritis. Russkii meditsinskii zhurnal. 2015; (10):575-578. (In Russ.).
73.Sharapova EP, Kashevarova NG, Taskina EA, et al. Study of the efficacy, tolerability and safety of Chondroguardin patients with osteoarthritis of the knee joints and comorbidity. Farmateka.2017; (7):46-51. (In Russ.).

74. Udovika MI. Comparative effectiveness of injectable and oral symptomatic slow action drugs in the treatment of primary and posttrau- matic osteoarthritis of the knee joints. Russkii meditsinskii zhurnal. 2017; (7):446-450. (InRuss.).

75.Singh G, Alekseeva L, Alekseev V, Nasonov E, et al., Combination treatment with glucosamine- chondroitin sulfate reduces pain, disability and NSAID consumption in patients with chronic low back pain: final results from a large, com- munity based, pilot, open prospective interven-tional study. Annals of the Rheumatic Diseases. 2014; 73(2): 300. THU0341. DOI: 10.1136/annrheumdis2014-eular.1035 